\title{
MPB LITERÁRIA: FERRAMENTA PEDAGÓGICA PARA INTRODUÇÃO AOS ESTUDOS LITERÁRIOS NO SEGUNDO CICLO DE ENSINO FUNDAMENTAL
}

Eneida da Silva Fiori ${ }^{\mathrm{i}}$

\begin{abstract}
Resumo: Este relato apresenta uma análise sobre a Música Popular Brasileira como ferramenta pedagógica de ensino para a introdução aos estudos literários em turmas do segundo segmento do ensino fundamental. Para discutir tal questão, um projeto foi iniciado em duas turmas de pré-adolescentes de uma escola da rede privada, na cidade de São Gonçalo, no ano de 2011. Tal projeto propunha estimular o conhecimento sobre Literatura a partir de letras de músicas articuladas com outras expressões artísticas como poemas e pinturas. A partir das aulas ministradas e das atividades realizadas pelos alunos foi possível compreender como a música contribui de maneira positiva para o envolvimento e o interesse dos alunos com relação ao conteúdo proposto.
\end{abstract}

Palavras-chave: Música popular; Literatura; Ensino fundamental.

\section{MPB LITERARIO: HERRAMIENTA PEDAGÓGICA PARA INTRODUCCIÓN A ESTUDIOS LITERARIOS EN EL SEGUNDO CICLO DE EDUCACIÓN FUNDAMENTAL}

Resumen: Este informe presenta un análisis de la música popular brasileña como una herramienta pedagógica para la introducción a los estudios literarios en las clases del segundo segmento de la escuela primaria. Para discutir este tema, se inició un proyecto en dos grupos de preadolescentes de una escuela privada en la ciudad de São Gonçalo, en el año 2011. Dicho proyecto propuso estimular el conocimiento sobre Literatura a partir de letras de canciones articuladas con otras expresiones artísticas como poemas y pinturas. A partir de las clases impartidas y las actividades realizadas por los estudiantes, fue posible comprender cómo la música contribuye positivamente a la participación e interés de los estudiantes en relación con el contenido propuesto.

Palabras-clave: Música popular; Literatura; Escuela primaria.

\section{Introdução}

Quando os alunos chegam ao ensino médio se deparam com algumas novidades nos seus currículos escolares. E uma delas é o ensino de Literatura. É comum, ao ministrar suas aulas, o professor de Literatura ouvir perguntas como: Por que eu devo estudar Literatura? Para que serve a Literatura? E mais comum ainda é a turma encontrar um professor que não saiba explicar, pelo menos com argumentos plausíveis e convincentes, a importância desta disciplina para a formação não só acadêmica, mas intelectual e cultural desses adolescentes. Talvez, o que mais confunda a cabeça deles é pensar que se esta disciplina é tão importante, por que não começarmos a estudá-la desde o ensino fundamental? É de se concordar que, se a literatura fizesse parte do currículo do ensino fundamental e os educandos tivessem contato com a arte 
desde cedo, o ensino da disciplina no ensino médio estaria em outro nível, ultrapassando as simples análises estruturais de poemas e identificação de características de escolas literárias.

A introdução à arte literária a partir da pré-adolescência estimularia a procura e o interesse dos discentes pelo conteúdo e tornaria possível acompanhar o seu crescimento não só físico, mas intelectual, comparando suas atuações em cada segmento. Trata-se de antecipar a introdução dos alunos a uma disciplina que aborda saberes como: o conhecimento, o conhecimento pertinente, a identidade humana, a compreensão humana, a incerteza, a condição planetária e a antro-poética; saberes estes, considerados por Morin (2001, p.1), necessários à educação do futuro, uma vez que "dizem respeito aos setes buracos negros da educação, completamente ignorados, subestimados ou fragmentados nos programas educativos". Programas esses que, em sua opinião, “devem ser colocados no centro das preocupações sobre a formação dos jovens, futuros cidadãos" (MORIN, 2001, p. 1).

Com o objetivo de encontrar uma metodologia em que eu pudesse tornar as aulas de Literatura, para turmas do ensino fundamental, mais interessantes, marcantes e produtivas, resolvi buscar por uma ferramenta que me auxiliasse de maneira eficaz na busca pelo meu objetivo. Precisava ser algo tocante, que fizesse parte do cotidiano dos alunos e que os unissem - apesar das diferenças - por um interesse comum. Foi assim que eu encontrei a música popular brasileira: minha ferramenta pedagógica para a introdução aos estudos literários nos ciclos finais do ensino fundamental.

Guiando-me pela perspectiva de que a música e a Literatura caminham bem juntas, justamente, "pela forma como conduzem as criações humanas: uma pelo jogo de sons, a outra pelo jogo de palavras" (MELO, 2005, p. 01), apresento no respectivo trabalho, um projeto realizado em 2011 em uma escola da rede privada, da região de São Gonçalo - no Rio de Janeiro, onde pus em prática meus planos de aulas cujo objetivo era possibilitar aos alunos, do sexto e do sétimo ano do ensino fundamental, um espaço de discussão em que eles pudessem compreender e aprender um pouco da arte literária, conhecer novos autores, interpretar os textos lidos, permitir ouvir a opinião do outro, expor sua própria opinião, exercitar o respeito ao próximo e às diferenças do outro e formar/repensar seus valores éticos e morais.

\section{Uma discussão acerca da prática de leitura proposta pelos parâmetros curriculares nacionais}

Segundo os Parâmetros Curriculares Nacionais de Língua Portuguesa (PCN, 1998) - terceiro e quarto ciclos do ensino fundamental - é de suma importância trabalhar os mais diversos gêneros textuais, não apenas em sua função de relevância social, mas também pelo fato que textos pertencentes a diferentes gêneros são organizados de diferentes formas (PCN, 2008, p. 23), o que dá aos alunos maior diversidade de meios para a compreensão, interpretação e reflexão dos textos e das temáticas que podem ser discutidas através dos textos, inclusive os temas transversais propostos pelos próprios PCN (1998). Como é através 
do texto que a linguagem se materializa, é preciso assegurar que o aluno tenha contato com esta diversidade textual. Para boa parte dos alunos, a escola é o único lugar em que se tem contato com textos escritos e, nestes casos, existe uma reação, nem sempre positiva, à prática de leitura, já que o texto escrito é um gênero completamente novo, o que pode fazer com que alguns professores resistam às novas tentativas/estratégias de leitura, acreditando que textos de qualidade possam ser difíceis de serem trabalhados. Para os PCN (1998):

A visão do que seja um texto adequado ao leitor iniciante transbordou os limites da escola e influiu até na produção editorial. A possibilidade de se divertir com alguns dos textos da chamada literatura infantil ou infanto-juvenil, de se comover com eles, de fruí-los esteticamente é limitada. Por trás da boa intenção de promover a aproximação entre alunos e textos, há um equívoco de origem: tenta-se aproximar os textos - simplificando-os - aos alunos, no lugar de aproximar os alunos a textos de qualidade. (PCN, 2008, p. 26)

Antes de qualquer discussão é preciso esclarecer a que tipo de prática de leitura me refiro. Entendese por prática de audição de textos orais e leitura de textos escritos, o trabalho a partir de textos que permitam aos professores orientar seus alunos quanto às especificidades dos gêneros, análises das temáticas discutidas, identificação e diferenciação dos tipos de linguagem, seleção dos gêneros textuais de acordo com os objetivos da leitura e, a inteira compreensão da leitura realizada, pois, assim como afirma Angela Kleiman (2002): "a leitura é um ato social, entre dois sujeitos - leitor e autor - que interagem entre si, obedecendo a objetivos e necessidades socialmente determinados."

Quando se fala em textos literários para o ensino fundamental, os mesmos gêneros vêm à tona: poema, Literatura infantil ou Literatura infanto-juvenil. Não se pensa a Literatura com o seu real e importante papel ante a sociedade: promover, através da arte, a reflexão sobre o mundo e suas condições de vida/vivência. A Literatura, que é apresentada aos alunos apenas no ensino médio, é trabalhada como mostra de obra de arte, em que se conhecem autores e suas obras, épocas literárias e suas características, poemas e sua estrutura, etc. Ainda que haja a contextualização histórica, dificilmente é proposta nas salas de aula uma discussão sobre se e como a arte era/é capaz de interferir na postura da sociedade ou como ela foi/é utilizada para problematizar questões sociais. Assim como propõem os próprios PCN (1998):

Como representação - um modo particular de dar forma às experiências humanas o texto literário não está limitado a critérios de observação fatual (ao que ocorre e ao que se testemunha), nem às categorias e relações que constituem os padrões dos modos de ver a realidade e, menos ainda, às famílias de noções/conceitos com que se pretende descrever e explicar diferentes planos da realidade (o discurso científico). Ele os ultrapassa e transgride para constituir outra mediação de sentidos entre o sujeito e o mundo, entre a imagem e o objeto, mediação que autoriza a ficção e a reinterpretação do mundo atual e dos mundos possíveis. (2008, p. 26) 
A Literatura não consiste apenas em apresentar aos alunos os textos propostos pelos livros, mas uma discussão acerca de como é possível interpretá-los a partir do conhecimento de mundo particular de cada um. É preciso observar que a "relevância do letramento literário reside em reconhecermos que é por meio da arte, e nesse caso específico, por meio da Literatura - sem desconsiderar outros discursos como o filosófico, por exemplo - que podem ser realizados inúmeros questionamentos que levam os indivíduos à reflexão acerca de sua condição" (GRIJÓ, 2007, p. 96). Assim, pode-se ter uma troca de experiências, capaz de transformar o aluno em sujeito crítico, que reflete, discute e repensa a sua realidade e a do seu próximo. Desta forma:

[...] pensar sobre a literatura a partir dessa relativa autonomia ante outros modos de apreensão e interpretação do real corresponde a dizer que se está diante de um inusitado tipo de diálogo, regido por jogos de aproximação e afastamento, em que as invenções da linguagem, a instauração de pontos de vista particulares, a expressão da subjetividade podem estar misturadas a citações do cotidiano, a referências indiciais e, mesmo, a procedimentos racionalizantes. Nesse sentido, enraizando-se na imaginação e construindo novas hipóteses e metáforas explicativas, o texto literário é outra forma/fonte de produção/apreensão de conhecimento. (PCN, p. 26)

Para Rojo (2004), que inicia seu artigo "Letramento e capacidades de leitura para cidadania", com a conhecida frase de Ziraldo: "Ler é melhor que estudar", a leitura deve ter finalidades - ler para estudar, ler para trabalhar, ler para informar-se ou para atualizar-se - o que faz com que tenha sentido. Ela relembra também que, embora grande parte da população brasileira tenha condições de estudar, a leitura ainda faz parte dos costumes da elite e não das grandes massas. Rojo afirma ainda que:

[...] ser letrado e ler na vida e na cidadania é muito mais que isso: é escapar da literalidade dos textos e interpretá-los, colocando-os em relação com outros textos e discursos, de maneira situada na realidade social; é discutir com os textos, replicando e avaliando posições e ideologias que constituem seus sentidos; é, enfim, trazer o texto para a vida e colocá-lo em relação com ela. Mais que isso, as práticas de leitura na vida são muito variadas e dependentes de contexto, cada um deles exigindo certas capacidades leitoras e não outras (ROJO, 2004, p. 2).

Tornar os textos literários parte dos cotidianos dos alunos do ensino fundamental é aceitar que eles sejam - e são - capazes de compreender o mundo ao seu redor. Proporcioná-los um momento de reflexão e deixar que construam, com a mediação do professor, relações de sentido entre o que se aprende na escola, nos textos - sejam eles orais ou escritos - e na vida, é permitir que tenham a "cabeça bem-feita", ou seja, em vez de acumular o conhecimento, o educando procurar dispor de "uma aptidão geral para colocar e tratar os problemas e princípios organizadores que permitam ligar os saberes e lhes dar sentido" (MORIN, 2003, p.21). Para que isso seja possível, é necessário discutir o texto literário além da simples interpretação, proporcionando um momento de interação e troca de ideias entre os alunos. O professor, enquanto 
mediador, deve recuperar o contexto e situar a turma: falar sobre o autor e sua posição social, sobre a possível finalidade do texto, o tipo de leitor que é esperado, a valorização do tema e a posição ideológica defendida no texto. Permitir que os discentes façam uma leitura crítica e cidadã é ajudá-los a dialogar com o texto e não deixar que subordinem-se a ele. Trabalhar com adolescentes é explorar todos os caminhos possíveis para o crescimento, amadurecimento e formação de opinião. Para Morin (2003), é preciso explorar:

[...] o livre exercício da faculdade mais comum e mais ativa na infância e na adolescência, a curiosidade, que, muito frequentemente, é aniquilada pela instrução. [...] Trata-se de estimulá-la ou despertá-la, se estiver adormecida. Trata-se, desde cedo, de encorajar, de instigar a aptidão interrogativa e orientá-la para os problemas fundamentais de nossa própria condição e de nossa época (MORIN, 2003, p. 22).

Estimular o pensamento e o senso crítico do aluno, a partir da discussão de textos literários, é contribuir para a formação de um leitor e ajudá-lo a formar uma mentalidade que reconhece e valoriza os usos sociais da linguagem e o seu espaço na sociedade. "Isso significa que também são conteúdos da área os modos como, por meio da palavra, a sociedade vem construindo suas representações a respeito do mundo" (PCN, 1998, p. 40) e, iniciar este processo de amadurecimento da mentalidade do indivíduo ainda na adolescência é de extrema importância, pois "trata-se de um período da vida em que o desenvolvimento do sujeito é marcado pelo processo de (re)constituição da identidade, para o qual concorrem transformações corporais, afetivo-emocionais, cognitivas e socioculturais" (PCN, 1998, p. 45). E, é neste momento, em que a Literatura chega para unir-se ao professor nesta tarefa tão complexa que é a de propor meios de amadurecimento e crescimento intelectual aos alunos.

\section{O gênero musical e a sala de aula de literatura}

Desde o momento da geração de uma criança, ela tem contato com os sons, seja por ouvir uma música ou apenas por ouvir a voz da mãe. Durante toda a nossa vida estamos cercados pela música, desde a infância, quando conhecemos as canções de ninar, até a fase adulta, em que optamos pelas nossas preferências musicais. "La música es el arte del oído por excelencia. Siendo el oído el primer sentido que experimenta el ser humano (sexto mes de embarazo) y el último que pierde el moribundo" (RODRÍGUEZ, 2005. p. 44), é possível compreender porque a música é utilizada para fins terapêuticos ou fins políticoideológicos. A música, que proporciona inúmeras sensações no ser humano, está, "historicamente, inserida no campo das artes, com toda a conotação cultural e simbólica que isso acarreta" (MUSZKAT; CORREIA; CAMPOS. 2000. P. 71). Para Wisnik: 
[...] a música fala ao mesmo tempo ao horizonte da sociedade e ao vértice subjetivo de cada um, sem se deixar reduzir às outras linguagens. Esse limiar está fora e dentro da história. A música ensaia e antecipa aquelas transformações que estão se dando, que vão se dar, ou que deveriam se dar, na sociedade. (WISNIK, 1999, p. 13)

Considerando tais aspectos, instigo a discussão sobre a utilização da música como ponto inicial de estudo e reflexão nas aulas de Literatura, propondo a introdução aos estudos literários ainda no ensino fundamental - como já foi apresentado no capítulo anterior.

\section{A MPB: letras e debates}

Não é de hoje que se pode observar que a música e a história sociopolítica do Brasil percorrem caminhos paralelos já que, desde a época colonial, a música era utilizada como meio de diversão e expressão de pensamento, o que gerava desconforto aos, até então, governantes. Essa trajetória político-musical é registrada desde o século XVIII, quando a capital baiana ainda era prestigiada como a mais rica cidade brasileira no que se refere aos aspectos sociais e culturais. Assim como apresenta Caldas (2005), as expressões como:

Cantos e danças como a chula, a fofa, o lundu e a modinha, entre outros, passariam a incomodar, não só a todo-poderosa Corte portuguesa, mas também a Igreja, as autoridades e os estratos sociais mais altos da Colônia. A popularização destes ritmos, danças e folguedos, conhecidos também, em seu conjunto, por "danças dramáticas", adquiriram, no decorrer do tempo, caráter profano, isto é, secularizado. É claro, ao lado desta "profanidade" havia toda uma coreografia extremamente sensual, mas logo considerada imoral e subvertedora dos hábitos, costumes e comportamentos da sociedade. As autoridades, de sua parte, passariam a proibir todos os ritmos e danças por elas classificados como imorais (CALDAS, 2005, p. 31).

Devo, a princípio, explicar que, para esta pesquisa, tenho como base a música popular brasileira em seu sentido amplo. Entende-se, por esta amplitude, toda e qualquer manifestação musical popular, independente de influências estrangeiras, ritmos ou estilos - Bossa nova, samba, rock, pop, rap, pagode, funk, etc. - que todo e qualquer cidadão brasileiro tenha acesso. Pois, ao contrário dos anos 70, como afirma Napolitano (2002), que o ouvinte padrão de MPB era o jovem de classe média com acesso ao ensino médio e superior, hoje, é considerado ouvinte padrão de MPB todo e qualquer cidadão que tenha acesso à música brasileira de modo geral.

No gênero musical, que além de ser muito rico em carga semântica e lexical, é possível encontrar um vasto conteúdo para análise literária. Ao trabalhar um texto, seja ele oral ou escrito, os alunos passam pelos processos de apreciações estéticas e afetivas, pois ao ouvir/ler, eles reagem ao texto de alguma forma: 
interessam-se pelo gênero, identificam-se com a estética, sentem prazer, deixam-se levar, envolvem-se. Além destas apreciações, é possível, ainda, trabalhar as apreciações relativas a valores éticos e políticos: os educandos podem discordar ou concordar com texto, criticar a posição defendida ou as ideologias apresentadas. Para tais questões não há gênero mais rico e completo que a música. Ela proporciona a oportunidade de avaliar valores colocados em circulação importantes para a cidadania, conduz à discussão e à reflexão acerca de valores éticos e políticos, além de tornar o momento de estudo mais agradável, entretendo-os, pois "uma prática de leitura que não desperte e cultive o desejo de ler não é uma prática pedagógica eficiente" (PCN, 1998; p. 17).

É possível, através da música, debater temáticas de cunho social, importantes para a formação crítica do aluno. A exemplo disso, na música Apesar de você, de Chico Buarque, há uma denúncia sobre a época dos governos militares, em que pessoas eram torturadas e perdiam seu direito à indignação ou expressão. O cantor vai mais além, critica a Lei da anistia, aprovada em 1979, que consistia em perdoar "crimes de qualquer natureza relacionados com crimes políticos ou praticados por motivação política” (FAUSTO. 2001, p. 504). Leia-se o trecho:

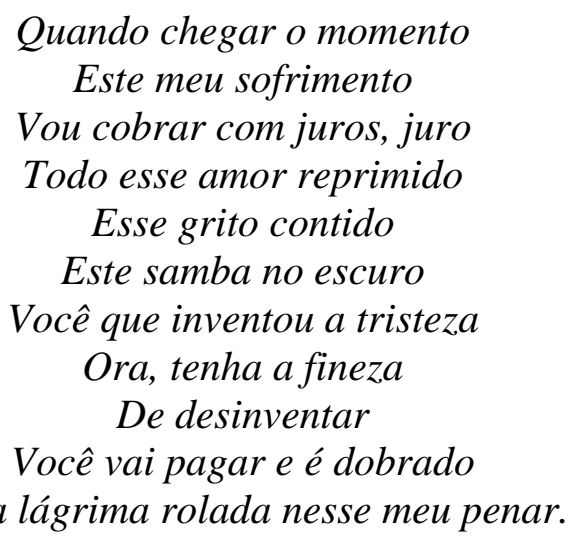

Além de Chico Buarque de Holanda, há muitos compositores que trazem em sua música denúncias sobre o governo ou opressões. Apesar de ainda ser um estilo musical considerado profano e subvertedor dos hábitos e costumes e, com isso, sofrer preconceitos por grande parte da sociedade, o Funk também traz consigo discussões políticas muito importantes. Se observarmos a letra da música Tá tudo errado, dos MCs Júnior e Leonardo, encontraremos uma discussão muito interessante sobre a ação da polícia nas favelas do Rio de Janeiro:

Não se combate crime organizado

Mandando blindado pra beco e viela

Pois só vai gerar mais ira

Na gente que mora dentro da favela

Sou favelado e exijo respeito 


São só meus direitos que eu peço aqui
Pé na porta sem mandado
Tem que ser condenado
Não pode existir
[...]
Mãe sem emprego
Filho sem escola
É o ciclo que rola naquele lugar
São milhares de histórias
Que no fim são as mesmas
Podem reparar
Sinceramente não tenho a saída
De como devia tal ciclo parar
Mas do jeito que estão nos tratando
Só estão ajudando esse mal se alastrar

Apesar da discussão sobre opressões e repressões serem inúmeras e de grande importância, este não é o único tipo de debate buscado aqui. A proposta é trabalhar com músicas que apresentem temáticas discutíveis, que acrescentem na formação daquele aluno enquanto leitor e cidadão, pois:

La música constituye una de las experiências existenciales más profundas del ser humano y elemento constitutivo fundamental de la configuración de nuestra personalidad, tanto individual (formación de nuestro yo) como de la identidad cultural de los pueblos o colectividades (RODRÍGUEZ, 2005, p. 44).

Por isso, é preciso aproveitar todo o tipo de manifestação musical que possa proporcionar aos alunos um momento de discussão e reflexão acerca de temáticas que competem também a eles enquanto cidadãos, sem fazer distinção ou estigmatizar um ou outro gênero musical específico.

\section{Conhecer/entender/descobrir o mundo através da música}

A ideia de se trabalhar a introdução aos estudos literários a partir do ensino fundamental propõe que os alunos passem pelos processos de estímulo e desenvolvimento de suas autonomias ainda na préadolescência, a fim de atentá-los, cada vez mais cedo, para a realidade em que vivem, a posição que ocupam e a reflexão sobre o que são e o que desejam ser. Pois, segundo os PCN (1998):

A busca de reinterpretação das experiências já vividas e das que passa a viver a partir da ampliação dos espaços de convivência e socialização possibilita ao adolescente a ampliação de sua visão de mundo, na qual se incluem questões de gênero, etnia, origem e possibilidades sociais e a rediscussão de valores que, reinterpretados, passam a constituir sua nova identidade. Desse ponto de vista, a formação do adolescente implica maior autonomia nas tomadas de decisão e no desempenho de suas atividades. Implica, ainda, a partir da nova percepção da realidade, dos direitos e deveres sociais e da responsabilidade crescente por seus 
atos, a constituição ou reformulação de valores e novos desdobramentos para o exercício da cidadania (PCN, 1998. p. 46).

Despertar os alunos para a vida não é simplesmente ensiná-los como e por que utilizar as variações da língua nem, ao menos, esperar que eles tornem-se leitores de quantidades em vez de leitores de qualidade. É mediar o conhecimento além do intelecto, é fazer parte da construção do ser crítico, é contribuir para a vida e a sua ascensão social. Em conformidade com os PCN (1998), o papel do professor de Língua Portuguesa é, acima de tudo, o de "mostrar ao aluno a importância que, no processo de interlocução, a consideração real da palavra do outro assume, concorde-se com ela ou não" (PCN, 1998, p. 47). Desta forma, o professor - mediador de conhecimento - permite que os educandos reconheçam o espaço do outro, troquem ideias e experiências e autoconheçam-se, iniciando, na sala de aula, a formação da sua própria identidade.

Para auxiliar de forma efetiva no processo de (re)conhecimento desses pré-adolescentes é importante, antes de tudo, ouvi-los e buscar compreendê-los, mas, para que os alunos pré-adolescentes permitam-se manifestar seus desejos e expor suas opiniões é preciso que sintam-se à vontade com o contexto em que estão inseridos. Por isso, a sala de aula deve ser apresentada não como um lugar onde há apenas a formação do conhecimento intelectual - passado do professor para os alunos, mas um lugar no qual eles possam identificar a troca de conhecimentos - de alunos para alunos, alunos para professor e professor para alunos.

Todo e qualquer texto carrega consigo as características e especificidades daquele que o escreve. Considerando que o mundo ao redor e seus acontecimentos influenciam na forma como o homem lê e compreende o espaço em que vive e que isso reflete na sua escrita, é possível afirmar que todo texto é carregado de uma leitura de mundo pessoal traduzido em escrita de palavras, à espera que alguém que faça a sua leitura enquanto palavra, se utilizando - para a compreensão - da leitura de mundo que tem. Para Freire (1989, p. 9) “a leitura do mundo precede a leitura da palavra, daí que a posterior leitura desta não possa prescindir da continuidade da leitura daquele”. Com a música não é diferente.

Como foi discutido no subtítulo anterior, há compositores que utilizam de suas expressões artísticas para expor suas opiniões de maneira que aquele que entre em contato com sua obra possa refletir e, talvez, compartilhar da mesma posição. Mas como pode o interlocutor compreender a discussão presente em uma música se ele nem ao menos conhece ou vive a realidade ali retratada? Cabe ao professor mediar o contato dos alunos com esta nova - ou não - realidade e selecionar um corpus que permita aos educandos conhecer um novo universo ou reconhecer o universo em que vivem. Freire (1989, p. 9) afirma que "linguagem e realidade se prendem dinamicamente". Afinal, o homem usa a linguagem como meio de expressar as suas verdades, sejam elas quais forem. Para que o leitor/ouvinte tenha uma leitura crítica eficaz, ele precisa ativar 
o seu conhecimento prévio, o conhecimento de mundo que lhe pertence, para que então, o texto e o contexto se ponham em harmonia e, assim, linguagem e realidade estejam em posições paralelas.

Após (re)conhecer a realidade discutida em sala, o aluno passa por um novo processo: entender como e por que esta realidade se estabelece. Para este processo os alunos devem ser instigados, pelos argumentos presentes no texto (leia-se música), a se questionarem e duvidarem do que está sendo apresentado, ativando seus conhecimentos de mundo, a fim de concluírem se a letra da música em questão trata-se de uma verdade, ou não. Melhor, se eles também compartilham daquela verdade. Afinal, mais importante que os alunos reconhecerem e entenderem a história de alguém, é eles se reconhecerem e entenderem a sua própria história. Para Descartes, o pai do Racionalismo, o homem deve ser instigado a pensar, não apenas porque ele tem este privilégio, mas porque o homem necessita da dúvida para dar sentido à sua existência. Segundo Guerra e Carvalho (2002, p. 51) "para Descartes, o pensamento se constituiria como um elemento que fundamentaria a existência do homem, no sentido de que a única "prova" da existência seria o ato de pensar, daí o axioma clássico: 'penso, logo existo"”. As autoras vão mais além, e desmembram o axioma de Descartes:

Em outras palavras, não se trataria de um sujeito que teria o privilégio de possuir, de antemão ideias e certezas, uma vez que ele se constituiria, reafirmamos, no seu curso de pensamento, sem qualquer certeza a priori que o regesse. (...) Nesse sentido, o axioma fundamental de Descartes teria se desmembrado em: "duvido, logo penso e se penso, logo existo". O que seria admitir que "se duvido, existo", uma vez que não haveria o ser sem o pensamento, nem o pensamento sem a dúvida (GUERRA; CARVALHO, 2002. p. 51).

A dúvida gera, então, o interesse pela descoberta. Se Cabral "descobriu" o Brasil, o que podem descobrir nossos alunos? O mundo. É comum durante a adolescência, os alunos viverem a época da "rebeldia", pois estão passando pela fase das descobertas. É nesta fase que os educandos começam a se conhecer e, com isso, vem a descoberta do mundo. E a música, tão comum em nossos cotidianos, pode ser o ponto de partida para o caminho, tanto de descobrimento do eu, quanto de descobrimento do outro e do mundo, permitindo aos discentes um novo olhar sobre a vida. Neste caso, o professor deve utilizar o binômio música-literatura interagindo "literatura e sociedade, arte e consciência, "eu" e mundo, relações estas já vislumbradas por Antônio Candido" (MELO, 2005, p. 01), de forma que proporcione aos seus alunos sucesso no processo da tão almejada descoberta.

\section{Colocando a tese em prática: uma experiência musical aplicada em sala de aula}

Ao iniciar meu trabalho na área da Literatura, em turmas do ensino fundamental, pus-me a pensar em um plano de aula que pudesse de maneira eficaz atrair meus alunos para as aulas, de forma que se 
sentissem estimulados a estudar um conteúdo que nem ao menos é obrigatório à grade deles. Iniciei o período de aulas com o sistema tradicional: conteúdo, quadro, textos literários, leituras e análises, dentro do alcance da turma, mas senti falta de um espaço em que eu pudesse ouvir os adolescentes e manter uma discussão que acrescentasse novidades a uma turma tão nova no meio literário. A busca era por um conteúdo que eles ainda não haviam conhecido em nenhuma outra disciplina, algo que acrescentasse aos alunos muito além do que aspectos intelectuais, aspectos socioculturais. Tanto quanto acrescentar a eles, eu precisava acrescentar à minha experiência como professora. Ao pesquisar novas metodologias, deparei-me com uma ferramenta de sucesso em meio aos alunos: a música. Então, elaborei um diferente plano de aula e iniciei a minha análise dentro de sala. Em conformidade com os PCN (1998), que pretendem apontar caminhos para um ensino mais voltado para o texto, a proposta era que os alunos pudessem aprender um gênero literário e, ao mesmo tempo, discutir questões socioculturais, tendo a oportunidade de expor suas opiniões, ouvir a dos colegas de classe e exercitarem o respeito às diferenças.

Foram trabalhados poemas, músicas e imagens, através dos quais os alunos analisaram os pontos de vista apresentados por cada autor e discutiram as temáticas segundo as suas experiências de vida. No sexto ano, foram trabalhados o poema $A$ vida, de Mário Quintana e a música $O$ que é, o que é, do Gonzaguinha. Enquanto no sétimo ano, a proposta foi A morte chega cedo, de Fernando Pessoa; a música Cedo ou tarde, da banda NX Zero e três imagens que remetiam o tema tratado nos textos. A escolha dos textos citados se deu, primeiramente, pela temática contida neles. Na turma dos alunos mais novos eu propus que a discussão fosse acerca da temática "vida"; enquanto na turma dos mais velhos, a temática era extremamente oposta, “morte”. Apoiando-se em Bakhtin (1992) e na teoria dos gêneros, o propósito era apresentá-los os gêneros e suas especificidades, as diferentes visões do eu lírico (de forma proposital, foram escolhidos textos que tratavam da mesma temática sobre diferentes olhares) sobre o mesmo tema e estimular, além da leitura, a expressão de forma oral. Desta forma, os alunos poderiam participar efetivamente da construção do seu próprio conhecimento.

Como se tratava de uma pesquisa metodológica, era necessário observar até onde a música os envolvia e estimulava a leitura dos poemas e a reflexão e discussão sobre os temas, já que o objetivo principal deste trabalho é de promover a inter-relação entre os conhecimentos de mundo e literários, utilizando a música como ponto de partida, no intuito de estimular e desenvolver o hábito da leitura - de mundo e de palavras -, a autonomia e o senso crítico dos educandos.

O resultado, em geral, foi muito positivo. Os alunos ficaram mais à vontade e expuseram sem receios as suas opiniões, demonstrando respeito à posição dos demais colegas de classe. Eles foram orientados por algumas perguntas que norteavam os principais pontos que deveriam ser discutidos em sala e, ao final da reflexão/discussão, eles fizeram uma atividade escrita (em anexo), na qual responderam as questões norteadoras. Além da atividade que envolvia os textos, solicitei que os alunos fizessem uma comparação 
entre as aulas anteriores, em que eram utilizados métodos tradicionais de ensino, e a aula do dia. E mais uma vez obtive um resultado positivo: os alunos redigiram algumas redações em que elogiavam a nova metodologia de ensino. Consideraram a aula mais dinâmica e afirmaram ter gostado da experiência de poder expor e ouvir opiniões. A atividade além de lúdica foi muito construtiva, pois permitiu que os alunos construíssem seu próprio conhecimento e reconhecessem a autonomia que têm em mãos. A proposta da música em sala de aula foi motivo não só de aprendizado e interesse dos alunos, mas de união entre eles, que propuseram para a aula seguinte que eles escolhessem as músicas que seriam utilizadas em sala. A turma reuniu um corpus de MPB e, dentre todas as músicas, escolheram aquela que, segundo eles, teria a proposta mais interessante para discussão naquele momento. A turma do sexto ano escolheu a música Máscara, da cantora Pitty, enquanto a turma do sétimo ano optou pela música $O$ calibre, dos Paralamas do Sucesso.

Como a primeira música fala sobre a aceitação da própria identidade, foi possível tecer discussões acerca das más e boas influências, do preconceito e da própria reflexão feita pela cantora. Aproveitando a música selecionada pela turma, elaborei as questões norteadoras e propus a produção de um desenho que os representassem de alguma forma, pois "através do lúdico, não se está perdendo uma evasão da realidade, mas, ao contrário, procura-se construir e recriar esta realidade" (ALVES, 1986, p. 86). Enquanto, na outra turma, que optou pela música dos Paralamas do Sucesso, que discute a situação de violência e descaso do governo vivido pela sociedade, a proposta foi apenas de produção escrita e oral. Como não poderia ser diferente, todos os alunos participaram ativamente de todas as atividades.

Mais que dinâmicas, as aulas foram a efetiva culminância da minha proposta. Ao ver meus alunos compartilhando o processo de seleção de material para suas aulas, discutindo sobre a relevância das temáticas propostas em cada música que compunha o corpus, decidindo juntos qual a letra que os deixava mais próximos de sua realidade e, ao mesmo tempo, divertindo-se com a dinâmica proposta por eles mesmos, eu pude concluir que a música, de fato, os uniu e os fez perceber a autonomia que têm em mãos.

\section{Relatos de alguns alunos}

Nenhum aluno é identificado neste trabalho, para respeitar a sua privacidade. 

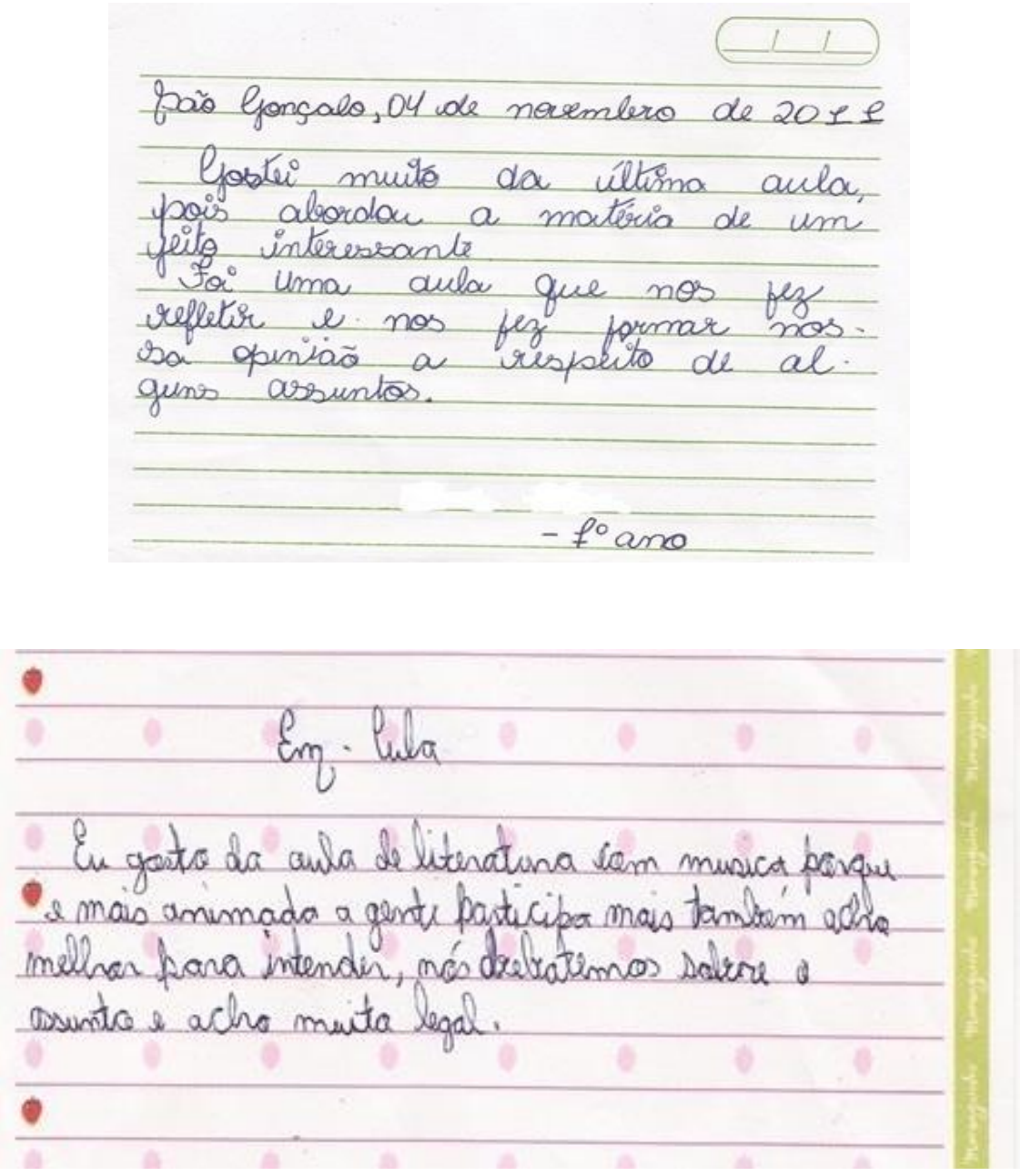

\section{Duscutindo Opiniórs}

Em rilaçä as aulas comunos ande aprendemos algo sobre a materia, prefiro as aulas em que discutimos assuntos diversificados e até mesmo desconhecidos para alguns alunos.

Clim de tornar as aulas mais dinámicas e divertidas aprendemos sobre assuntos nao discutedos em outras aulas comuns. Eै saĩ nessas aulas em além de assumilarmas rossan opinións e ideias com as de outras pessoas, apren. demos a aceitar a opiniáo atheia e até musmo mudar nossa própria opiniaio

$$
-7 \text { : ano }
$$




\section{Considerações Finais}

O presente trabalho foi construído a partir de uma longa pesquisa teórico-bibliográfica e de campo. Como pudemos verificar, o ensino de Literatura, proposto apenas para o ensino médio, muitas vezes perde a sua essência, passando de reflexão sobre a vida a partir da arte, para análise estrutural de poemas e obras literárias. Discutindo tal questão, este trabalho posiciona-se favorável ao ensino de Literatura a partir do ensino fundamental, propondo que seja realizada desde então a introdução dos alunos pré-adolescentes ao meio das artes, sem deixar que a essência da Literatura se perca.

Iniciando-se com a observação da produção dos alunos pesquisados, em aulas tradicionais, a pesquisa foi intensificando-se à medida que, baseando-se nas referências bibliográficas, consegui elaborar um novo plano de aula, na qual pude explorar a prática do pensamento. Para que a nova proposta de aula desse certo, foi preciso considerar todos os pontos discutidos neste trabalho: a prática de leitura proposta pelos PCN (1998), o conceito de MPB, a literatura no ensino fundamental e a música como ferramenta para a introdução dos alunos ao ensino da disciplina. Além de tais aspectos, foi necessário, ainda, reflexionar sobre o interesse dos alunos pela música.

Os pré-adolescentes pesquisados demonstraram um imenso interesse pela música popular brasileira, cada um com suas preferências de gênero e estilo, mas todos interessados, o que me remeteu a ideia de que a música, utilizada em sala de aula como ferramenta pedagógica de ensino, os impulsionaria para o aprendizado com prazer, resultando em alunos mais motivados a participar e, consequentemente, aprender. Assim como era esperado, o resultado foi muito satisfatório. $\mathrm{O}$ aproveitamento e a participação dos alunos nas atividades propostas durante as aulas em que utilizei a música como ferramenta foi de $100 \%$. Não houve um só aluno que não quisesse participar, todos se sentiram instigados a dar sua opinião no momento da discussão.

Utilizando tal ferramenta, considerando a criatividade e o desempenho do professor, e diante dos fatos apresentados, pude concluir que a música é, sem dúvidas, um instrumento facilitador e estimulador do processo de ensino-aprendizagem. Afinal, ela nos proporciona um extenso e rico acervo, retoma a cultura nacional nos mais diferentes aspectos, e traz à tona as mais variadas temáticas, permitindo ao professor levar à sua sala de aula inúmeras possibilidades para discussão e reflexão, o que auxiliará na formação de leitores críticos - de mundo e de palavras.

\section{Referências}

ALVES, R. A gestação do futuro. São Paulo: Papirus, 1986. 
BAKTHIN, M. Os gêneros do discurso. In: BAKTHIN, Mikhail. Estética da criação verbal. TRAD. PEREIRA, Maria Fernandina Galvão Gomes. São Paulo: Martins Fontes, 1992.

BRASIL. Secretaria de Educação. Parâmetros curriculares nacionais: Ensino Fundamental. Brasília: MEC, 1998.

CALDAS, W. A cultura político-musical brasileira . São Paulo: Musa Editora, 2005.

FREIRE, P. A importância do ato de ler: em três artigos que se completam. São Paulo: Autores Associados: Cortez, 1989.

GUERRA, A.; CARVALHO, G. Interpretação e método: repetição com diferença. Rio de Janeiro: Garamond, 2002.

KLEIMAN, A. Texto e leitor: aspectos cognitivos da leitura. Campinas: Pontes, 2002.

MELO, C. Música Popular Brasileira e Literatura: Um Estímulo Interdisciplinar Através dos Textos. Pesquisa apresentada no IV Encontro Ibero-americano de Coletivos Escolares e Redes de Professores que Fazem Investigação na sua Escola. 2005. Disponível em: <http://ensino.univates.br/ 4iberoamericano/trabalhos/trabalho069.pdf>. Acessado em: 13 nov. 11.

MORIN, E. Os sete Saberes Necessários à Educação do Futuro. 3. ed. São Paulo: Cortez; Brasília, DF: UNESCO, 2001.

MORIN, E. A cabeça bem-feita: repensar a reforma, reformar o pensamento. Tradução Eloá Jacobina. 8. ed. Rio de Janeiro: Bertrand Brasil, 2003.

MUSZKAT, M. et al. Música e Neurociências . Revista Neurociências. Vol. 8, No 2. Pág. 70-75, 2000.

NAPOLITANO, Marcos. A música popular brasileira (MPB) dos anos 70: resistência política e consumo cultural. s/p. 2002. Disponível em: 〈http://www.hist.puc.cl/iaspm/mexico/articulos/Napolitano.pdf>. acessado em: 13. Nov.11.

PAIVA, A. et al. Literatura: saberes em movimento. Belo Horizonte: Ceale, Autêntica, 2007.

RODRÍGUEZ, A. Musica y Literatura. Revista Archipielago. Ed. Universidad Nacional Autónoma de México. Vol. 13, No 47, s/p, 2005.

ROJO, R. Letramento e capacidades de leitura para a cidadania. São Paulo: SEE: CENP, 2004. Texto apresentado em Congresso realizado em maio de 2004.

WISNIK, J. M. O som e o sentido. São Paulo: Companhia das Letras. 1999.

Recebido em 18/05/2020

Aceito em 05/08/2020

Notas

i Professora de Língua Portuguesa com Licenciatura em Letras Português-Inglês (FFP/UERJ); Especialista em Educação Básica, com ênfase em Gestão Escolar (FFP/UERJ); Mestranda em Educação no Programa de Pós Graduação em Educação - Processos Formativos e Desigualdades Sociais (FFP/UERJ). E-mail: fiori_eneida@hotmail.com São Gonçalo, Rio de Janeiro. ORCID: https://orcid.org/0000-0002-5841-6100 